\title{
Влияние концентрации кислорода в составе газовой плазмообразующей смеси на оптические и структурные свойства пленок нитрида алюминия
}

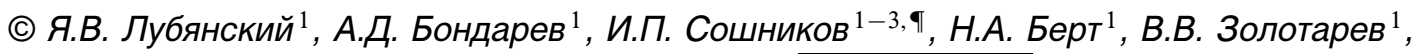 \\ Д.А. Кириленко ${ }^{1}$, К.П. Котляр ${ }^{2}$, Н.А. Пихтин ${ }^{1}$, И.С. Тарасов $^{1}$ \\ ${ }^{1}$ Физико-технический институт им. А.Ф. Иоффе Российской академии наук, \\ 194021 Санкт-Петербург, Россия \\ ${ }^{2}$ Академический университет, \\ 194021 Санкт-Петербург, Россия \\ ${ }^{3}$ Институт аналитического приборостроения Российской академии наук, \\ 190103 Санкт-Петербург, Россия \\ ^E-mail: ipsosh.beam@mail.ioffe.ru
}

(Получена 11 июля 2017 г. Принята к печати 19 июля 2017 г.)

\begin{abstract}
Проводятся исследования влияния содержания кислорода в плазмообразующей среде в процессах синтеза методом реактивного ионно-плазменного распыления на структуру и свойства пленок AlNO (оксинитридов алюминия). Измеренные показатели преломления синтезированных пленок AlNO находятся в диапазоне 1.76-2.035 и зависят от концентрации кислорода в плазмообразующей газовой смеси, а именно с увеличением доли кислорода показатель преломления уменьшается. Показано, что пленки AlN, синтезированные в плазме азота, имеют поликристаллическую текстурированную структуру. Повышение содержания кислорода приводит к образованию аморфной фазы.
\end{abstract}

DOI: 10.21883/FTP.2018.02.45443.8685

\section{1. Введение}

Развитие современных микро-, нано- и оптоэлектроник связано с миниатюризацией элементов и ростом их плотности в интегральных схемах, повышением общей мощности приборов. Традиционно применяемые для производства таких приборов диэлектрические материалы на основе оксидов кремния и(или) алюминия при таких условиях эксплуатации становятся источником деградационных процессов. Для создания широкого спектра приборных структур перспективным решением является применение нитрида алюминия (A1N): этот материал является изовалентным с основными материалами оптоэлектроники (III-V нитриды галлия, арсенид галлия). Кроме того, AlN имеет высокое значение ширины запрещенной зоны (6.1-6.2 эВ) [1], высокое значение коэффициента теплопроводности, которое в 10 и в 300 раз больше, чем у оксида алюминия $\left(\mathrm{Al}_{2} \mathrm{O}_{3}\right)$ и нитрида/оксида кремния $\left(\mathrm{Si}_{3} \mathrm{~N}_{4} / \mathrm{SiO}_{2}\right)$ [2] соответственно, диэлектрические свойства, прочностные характеристики [3], химическая устойчивость к ряду агрессивных сред, оптимальные значения коэффициента преломления и поглощения для широкого спектрального диапазона $[2,4,5]$. Указанные свойства позволяют применять нитрид алюминия в оптоэлектронной промышлености, в частности, как пассивирующее, просветляющее диэлектрическое покрытие для широкого спектра полупроводниковых лазеров $[2,4,6]$.

Выбор методов синтеза пленок AlN определяется требованиями технологии приборных структур, в частности: тонкие пленки AlN (до 1 мкм) возможно синтезировать методами молекулярно-пучковой эпитаксии [7-9], хими- ческого осаждения из газовой (паровой) фазы $[7,10,11]$, нитридизации поверхностных слоев [12-15], реактивного ионно-плазменого или магнетронного осаждения [7,16-19]. Процесс синтеза пленок нитрида алюминия методом молекулярной-пучковой эпитаксии является нетривиальным и дорогостоящим. Химическое осаждение из газовой (паровой) фазы и нитридизация в газовых средах также являются сложными и требуют использования токсичных и взрывоопасных газов. Кроме того, газофазное осаждение пленок AlN и(или) нитридизация производятся при высоких температурах $\left(\sim 500-900^{\circ} \mathrm{C}\right)$, что делает неприменимым этот метод для ряда приложений, в частности: формирование просветляющего покрытия полупроводникового лазера и(или) нанесение диэлектрического покрытия, так как при указанных температурах возможна деградация или негативное изменение уже сформированной структуры. В то же время методы ионно-плазменного синтеза пленок AlN позволяют проводить процессы при температурах образцов от 25 до $250^{\circ} \mathrm{C}$, что делает возможным решение задачи создания покрытий (пленок AlN на различных полупроводниковых структурах).

В представленной работе изучаются основные закономерности синтеза пленок нитрида алюминия методом реактивного ионно-плазменного распыления. Особое внимание в работе уделяется проблемам влияния кислорода на синтезируемую пленку нитрида алюминия: внедрение кислорода в структуру пленки, что в свою очередь приводит к структурным изменениям сформированного покрытия и изменению его оптических параметров. Как структурные, так и оптические изменения напрямую влияют на качество синтезируемого покрытия и создают 

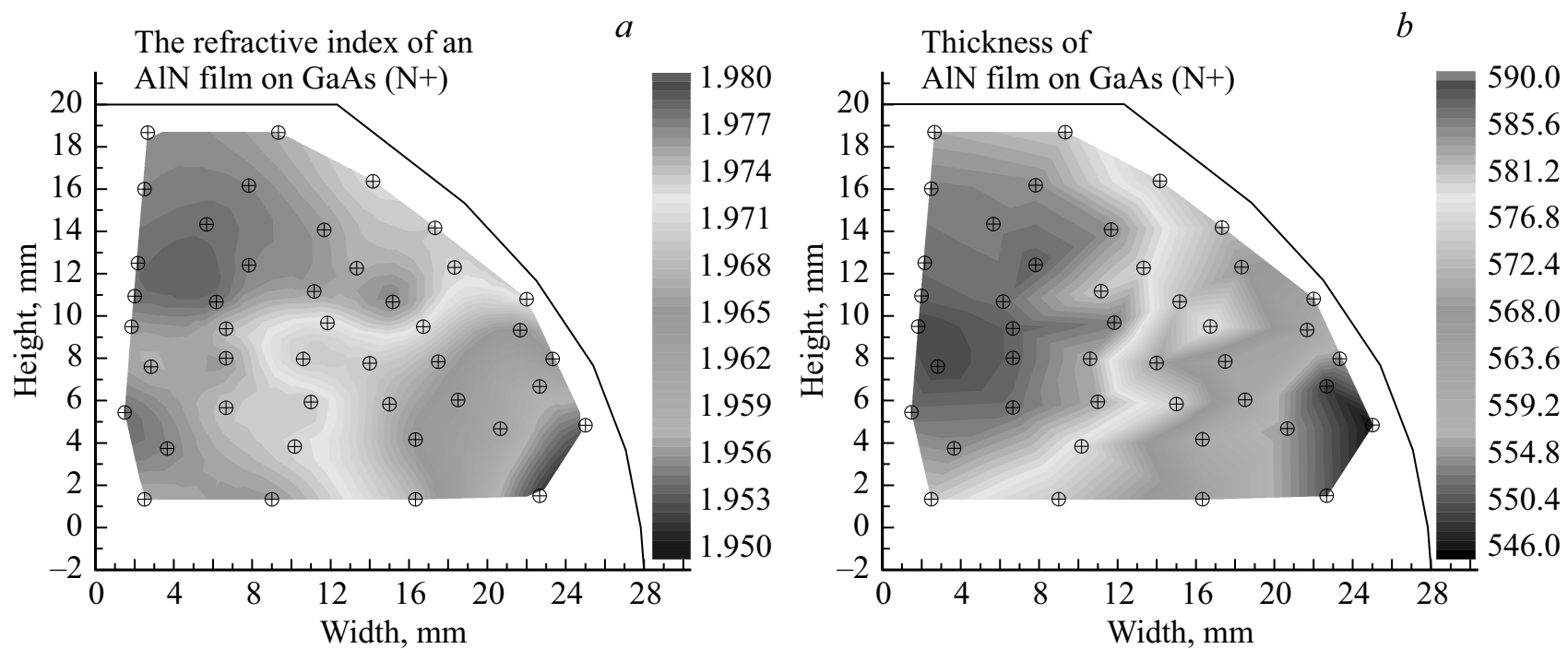

Рис. 1. Распределение показателя преломления $(a)$ и толщины $(b)$ по образцу с пленкой $\mathrm{AlN}$, синтезированной в плазме чистого азота.

препятствия для их дальнейшего использования в оптоэлектронных приборах, в частности, как оптического покрытия для мощных полупроводниковых лазеров.

\section{2. Экспериментальная часть}

Синтез пленок AlN был реализован методом реактивного ионно-плазменного распыления на установке УБ 15 1276 с триодной плазменной схемой и безмасляной вакуумной системой, обеспечивающей остаточное давление в рабочей камере не хуже чем $1 \cdot 10^{-7}$ Торр. Для проведения экспериментов использовались плазмообразующие газы: аргон, азот или смесь кислорода и азота с чистотой не хуже $99.999 \%$. Рабочее давление в камере варьировалось в диапазоне $(3-6) \cdot 10^{-4}$ Торр. В качестве мишени использовалась пластина прямоугольной формы из чистого алюминия $(99.999 \%)$. Для удаления естественного оксидного слоя мишень предварительно обрабатывается ионной плазмой аргона в течение 10 мин при напряжении около $400 \mathrm{~B}$. В качестве подложек использовались пластины GaAs (100) площадью от 1 до $10 \mathrm{~cm}^{2}$ и толщиной до 500 мкм.

Исследования структуры выращенных образцов проводились методами электронной микроскопии (ПЭМ Jeol JEM-2100F, оборудованный рентгеновским спектрометром INCA Oxford Instruments, и РЭМ Supra 25 C. Zeiss). Подготовка образцов для исследования методом ПЭМ в геометрии поперечного сечения проводилась по стандартной методике, включающей склеивание фрагментов исходной структуры лицевыми поверхностями друг к другу, механическую шлифовку заготовки до толщин около 20 мкм с последующим ионным травлением $\mathrm{Ar}^{+}$при энергиях 4 кэВ. Оценка содержания кислорода в пленках AlN проводилась по данным рентгеноспектрального микроанализа, полученным в ПЭМ. Ана-

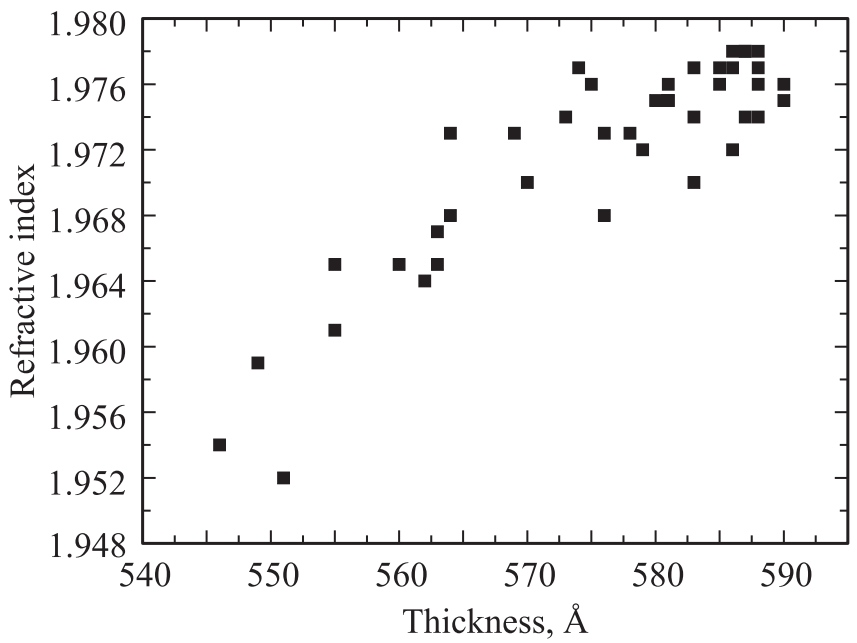

Рис. 2. Соотношение показателя преломления и толщины пленки AlN, синтезированной в плазме чистого азота.

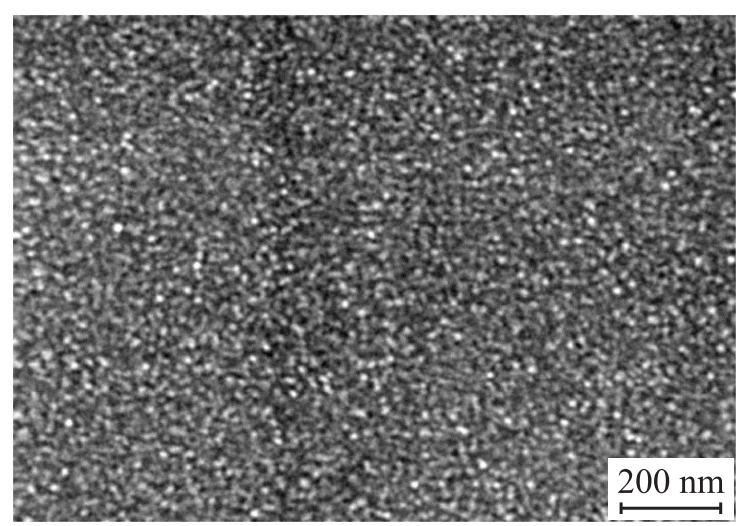

Рис. 3. РЭМ изображение поверхности пленки AlN с показателем преломления 2.035, синтезированной в плазме чистого азота. 


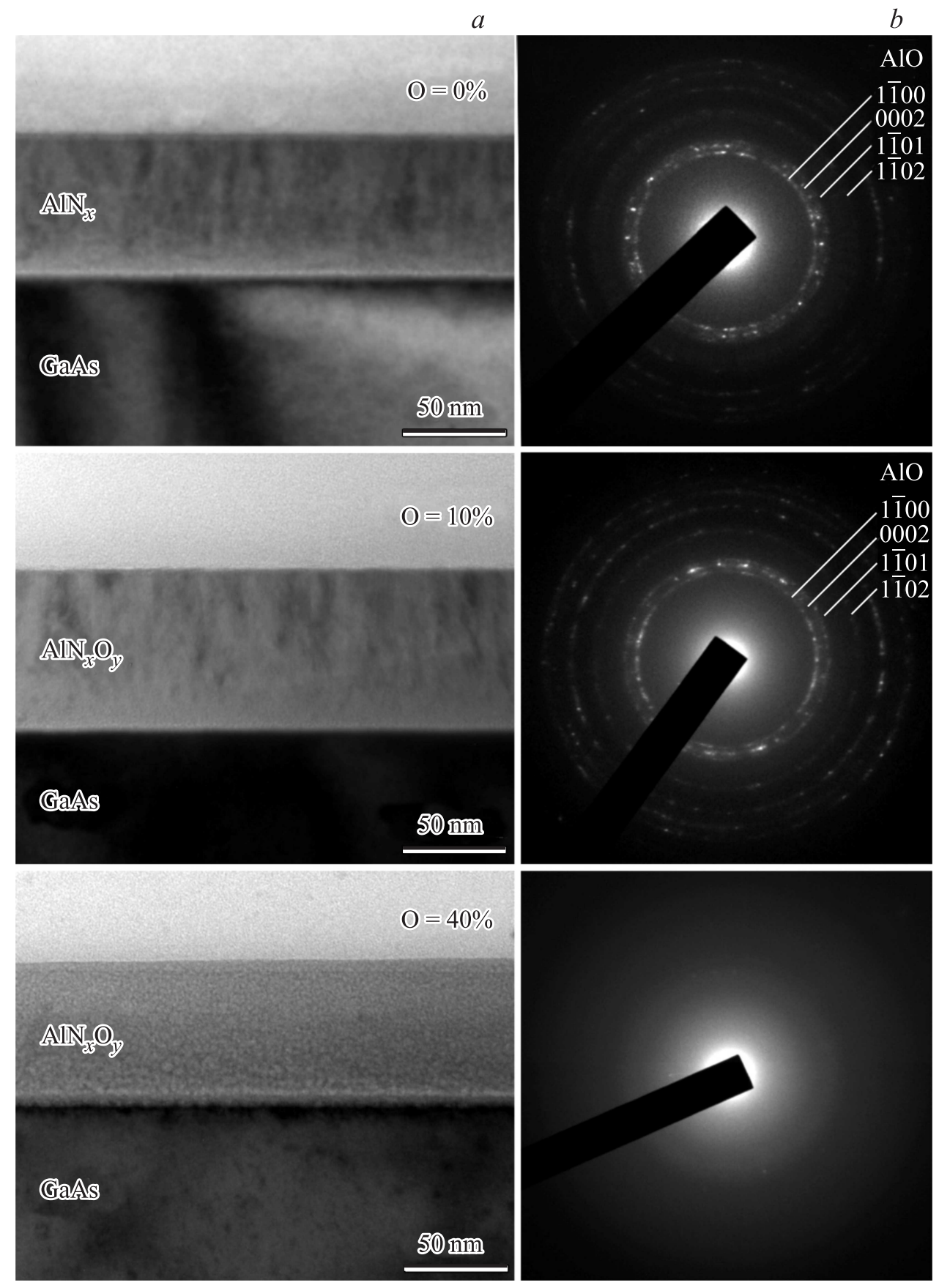

Рис. 4. Светлопольные изображения $(a)$ и картины электронной дифракции $(b)$ поперечных сечений пленок с содержанием кислорода $x=0,10,40 \%$.

лиз изображений проводился с помощью специальной программы DIAnaTEM [20]. Измерение коэффициента преломления проводилось на эллипсометре Horiba на длине волны 633 нм.

\section{3. Результаты и обсуждение}

Во время исследования были синтезированы пленки оксинитридов алюминия с использованием плазмообра- зующих смесей газов азота и кислорода с процентным содержанием кислорода $0,10,40 \%$. Толщина синтезированных пленок в проводимых экспериментах составляет от 50 до 400 нм. Величины скорости синтеза пленок приведены в таблице.

Пленки, полученные при использовании чистого азота в качестве плазмообразующего газа и предварительным тренингом мишени, имеют коэффициент преломления в диапазоне от 1.95 до 2.035. Примеры дисперсии показателя преломления и толщины синтезируемых пленок на 
Влияние состава плазмообразующей смеси на параметры процессов синтеза и характеристики пленок

\begin{tabular}{c|c|c|c|c|c|c}
\hline $\begin{array}{c}\text { Состав } \\
\text { газовой смеси }\end{array}$ & $\begin{array}{c}\text { Скорость } \\
\text { роста, нм/сек }\end{array}$ & $\begin{array}{c}\text { Толщина } \\
\text { аморфного слоя, нм }\end{array}$ & $\begin{array}{c}\text { Латеральный размер } \\
\text { кристаллитов, нм }\end{array}$ & $\begin{array}{c}\text { Размер кристаллитов } \\
\text { по высоте, нм }\end{array}$ & $\begin{array}{c}\text { Показатель } \\
\text { преломления }\end{array}$ & Адгезия \\
\hline $0 \% \mathrm{O}_{2}$ & $13 \mathrm{Hм} /$ мин & $\leq 2-3$ & $10-15$ & $\begin{array}{c}\text { Порядка } \\
\text { толщины пленки }\end{array}$ & $1.93-2.035$ \\
\hline $10 \% \mathrm{O}_{2}$ & $12 \mathrm{Hм} /$ мин & $4-10$ & $\leq 10$ & $\begin{array}{c}\text { Зависит от толщины } \\
\text { аморфного слоя }\end{array}$ & $1.85-1.8$ & + \\
\hline $40 \% \mathrm{O}_{2}$ & $10.8 \mathrm{Hм} /$ мин & $\begin{array}{c}\text { По всей } \\
\text { толщине пленки }\end{array}$ & - & - & $\leq 1.8$ или \\
не измеримо
\end{tabular}

образце продемонстрированы на рис. 1 соответственно. Видно, что дисперсия значений коэффициента преломления и толщины составляет порядка 0.03 и менее 5.4 нм соответственно. Сопоставление дисперсии коэффициента преломления и толщины показывает корреляцию между ними (рис. 2), которая может объясняться особенностями влияния температурных и плазменных полей по образцу.

Исследования поверхностной морфологии методом РЭМ в геометрии поперечного сечения и изометрии показывают, что полученные пленки имеют гладкую поверхность с отдельными дефектами, которые возникают вследствие загрязнения поверхности на этапе подготовки образцов. В исследованиях РЭМ изображений в геометрии plan view на пленках, полученных при синтезе в чистом азоте, наблюдается наноразмерный контраст (рис. 3). При увеличении содержания кислорода до $10 \%$ наблюдается существенное снижение контраста, а при $40 \%$ - контраст не выявляется. По-видимому, наблюдаемый контраст обусловлен образованием поликристаллической структуры AIN и отсутствует для аморфных пленок AlNO.

Исследования методом ПЭМ (рис. 4) показывают, что структура пленок AlN, синтезированных в плазме чистого азота, является поликристаллической вюрцитного типа. Характерные размеры нанокристаллитов составляют порядка 10-15 нм в латеральном направлении и соответствуют толщине пленки в высоту. В ряде случаев отмечается образование текстурированных пленок с осью $C$, ориентированной преимущественно нормально к поверхности образца.

В структуре таких пленок наблюдается аморфный слой оксинитрида алюминия, прилегающий к подложке, и выше поликристаллический слой нитрида алюминия. (рис. 4). Отмечается, что толщина аморфного слоя оксинитрида алюминия зависит от окисленности поверхности мишени и образца (характерные размеры кристаллитов приведены в таблице). При обеспечении удаления окислов аморфный слой может не наблюдаться.

Адгезия пленок с аморфным слоем оксинитрида алюминия, как правило, выше, чем в случае синтеза пленок AlN без аморфного слоя. Указанное, по-видимому, обусловлено градиентом структурных напряжений на границе подложка-слой. Наличие структурных напря- жений связано с большим рассогласованием решеток на границе двух материалов $\left(\mathrm{a}_{\mathrm{GaAs}}=5.65 \AA, \mathrm{a}_{\mathrm{AlN}}=4.4 \AA\right.$ (расч.)), что и приводит к ухудшению адгезионных свойств синтезируемых пленок. Наличие ультратонкого слоя оксинитрида служит буферным слоем, сглаживающим структурные напряжения. При этом малый размер такого слоя не приводит к каким-либо ощутимым изменениям оптических параметров пленок AIN (изменению показателя преломления). Причина формирования такого слоя состоит из нескольких факторов. Наличие естественного оксидного покрытия на поверхности GaAs [21] и присутствие кислорода в смеси плазмообразующего газа, в том числе как остаточного кислорода после предварительной подготовки вакуума системы [22]. Указанные причины образования оксидной пленки носят случайный характер, т.е. параметры толщины и „чистоты“ таких окислов слабо контролируемы и имеют существенную дисперсию ( 100\%).

При синтезе пленок в атмосфере с содержанием кислорода $\sim 10$ и 40\% наблюдается снижение коэффициента преломления до величин в диапазоне от 1.85 и ниже. Исследования ПЭМ показывают, что пленки имеют аморфную структуру с отдельными включениями кристаллитов (рис. 4). Характерные размеры (см. таблицу) таких нанокристаллитов составляют от $10 \mathrm{Hм}$ и меньше в латеральном направлении и соответствуют толщине пленки (без учета толщины аморфного слоя) в вертикальном направлении. Плотность нанокристаллических включений с увеличением содержания кислорода существенно снижается от $15 \cdot 10^{-12} \mathrm{~cm}^{-2}$ вплоть до отдельных включений (рис. 4).

\section{4. Заключение}

В работе экспериментально изучено влияние содержания кислорода в плазмообразующей смеси газов на структуру пленок AlNO. Показано, что при синтезе с использованием чистого азота образуется поликристаллическая пленка нитрида алюминия с характерными размерами нанокристаллитов порядка 10-20 нм в латеральном направлении и до толщины пленки (50-400 нм) в нормальном направлении к поверхности. Характерное значение показателя преломления для таких пленок 
составляет $2.00 \pm 0.05$. При добавлении кислорода в плазмообразующую смесь газов наблюдается образование аморфных пленок оксинитрида с нанокристаллическими включениями. Величина показателя преломления для таких пленок снижается до 1.75. Отмечается, что наилучшая адгезия пленок наблюдается для образцов с ультратонким слоем оксинитрида галлия, что объясняется релаксацией структурных напряжений на аморфном слое.

Работа выполнена при поддержке РФФИ (гранты 16-29-03113 офи_м, 15-07-06964 А), программы президиума РАН, с использованием оборудования федерального ЦКП „Материаловедение и диагностика в передовых технологиях“ (ФТИ им. А.Ф. Иоффе, Санкт-Петербург).

\section{Список литературы}

[1] M.O.H.D. Al Rashdan, A.A. Hamzah, B.Y. Majlis, M.F. Aziz. IEEE Intern. Conf. on Semiconductor Electronics, ICSE 2014 (Institute of Electrical and Electronics Engineers Inc.) p. 72, p. 6920798 (2014).

[2] L. Zhou, X. Gao, Y. Wang, L. Xu, B. Jia, D. Bai, B. Bo. J. Lightwave Techn., 31 (13), 2279 (2013).

[3] P. Pobedinskas, J.C. Bolsée, W. Dexters, B. Ruttens, V. Mortet, J. D’Haen, K. Haenen. Thin Sol. Films, 522, 180 (2012).

[4] A. Jagoda, L. Dobrzanski, M. Modonek, S. Wrobel. J. Wide Bandgap Mater., 8 (3-4), 195 (2001).

[5] H. Van Bui, F.B. Wiggers, A. Gupta, M.D. Nguyen, A.A. Aarnink, M.P. de Jong, A.Y. Kovalgin. J. Vacuum Sci. \& Techn. A: Vacuum, Surfaces, and Films, 33 (1), 01A111 (2015).

[6] J. Liao, S.H. Liu, Y.T. Yu, Y. Lin, G. Jin, G. Huang, Z.Z. Fu. IEEE 2011 Intern. Symp. on Advanced Packaging Materials (APM 2011) p. 373.

[7] А.Ф. Белянин, А.Ю. Илюшенкин. Технология и конструирование в электронной аппаратуре, 5, 35 (2005).

[8] M.E. Lin, B. Sverdlov, G.L. Zhou, H. Morkoç. Appl. Phys. Lett., 62 (26), 3479 (1993).

[9] F. Semond, Y. Cordiez, N. Grandjeen, F. Natali, B. Demilano, S. Vezian. Phys. Status Solidi A, 188 (2), 501 (2001).

[10] P. Lu, R. Collazo, R.F. Dalmau, G. Durkaya, N. Dietz, B. Raghothamachar, M. Dudley, Z. Sitar. J. Cryst. Growth, 312 (1), 58 (2009).

[11] I. Bryan, A. Rice, L. Hussey, Z. Bryan, M. Bobea, S. Mita, J. Xie, R. Kirste, R. Collazo, Z. Sitar. Appl. Phys. Lett., $102(6), 061602$ (2013).

[12] Л.А. Акашев, Н.А. Попов, В.А. Кочедыков, В.Г. Шевченко. ПЖТФ, 39 (3), 26 (2013).

[13] А.В. Кириллин, А.В. Костановский, Л.А. Жиляков. Теплофизика высоких температур, 27 (6), 1185 (1989).

[14] Л.А. Жиляков, А.В. Костановский. Теплофизика высоких температур, 30 (2), 290 (1992). (High Temperature, 30 (2), 226 (1992)).

[15] Л.А. Жиляков, А.В. Костановский, А.В. Кириллин. Теплофизика высоких температур, 33 (1), 33 (1995). (High Temperature, 33 (1), 30 (1995)).

[16] A. Stolz, A. Soltani, B. Abdallah, J. Charrier, D. Deresmes, P.-Y. Jouan, M.A. Djouadi, E. Dogheche, J.-C. De Jaeger. Thin Sol. Films, 534, 442 (2013).
[17] V. Brien, P. Pigeat. J. Cryst. Growth, 310 (16), 3890 (2008).

[18] V.V. Kirilenko, B.M. Zhigarnovskiǔ, V.K. Pavlovskiǔ, I.P. Markelova, A.V. Mikhaŭlov, G.A. Muranova. J. Optical Techn., 75 (12), 800 (2008).

[19] P. Pobedinskas, J.-C. Bolsée, W. Dexters, B. Ruttens, V. Mortet, J. D'Haen, J.V. Manca, K. Haenen. Thin Sol. Films, 522, 180 (2012).

[20] И.П. Сошников, О.М. Горбенко, А.О. Голубок, Н.Н. Леденцов. ФТП, 35 (4), 361 (2001).

[21] А.В. Анкудинов, В.П. Евтихиев, В.Е. Токранов, В.П. Улин, А.Н. Титков. ФТП, 33 (5), 594 (1999).

[22] Н.А. Берт, А.Д. Бондарев, В.В. Золотарев, Д.А. Кириленко, Я.В. Лубянский, А.В. Лютецкий, С.О. Слипченко, А.Н. Петрунов, Н.А. Пихтин, К.Р. Аюшева, И.Н. Арсентьев, И.С. Тарасов. ФТП, 49 (10), 1429 (2015).

Редактор Г.А. Оганесян

\section{Effect of oxygen concentration in a gas plasma-forming mixture on the optical and structural properties of aluminum nitride films}

Ya.V. Lubyanskiy ${ }^{1}$, A.D. Bondarev ${ }^{1}$, I.P. Soshnikov ${ }^{1-3}$, N.A. Bert ${ }^{1}$, V.V. Zolotarev ${ }^{1}$, D.A. Kirilenko ${ }^{1}$, K.P. Kotlyar ${ }^{2}$, N.A. Pikhtin ${ }^{1}$, I.S. Tarasov ${ }^{1}$

${ }^{1}$ loffe Institute, 194021 St. Petersburg, Russia

${ }^{2}$ St. Petersburg Academic University, 194021 St. Petersburg, Russia

${ }^{3}$ IAI Russian Academy of Sciences, 190103 St. Petersburg, Russia

Abstract In the work, the effect of the oxygen content in the plasma-forming mixture in the synthesis processes by reactive ionplasma sputtering on a structure and optical properties of AlNO (aluminum oxynitrides) films is studied. The measured refractive indices of the synthesized AlNO films range from 1.76 to 2.035 and depend on the oxygen concentration in the plasma-forming gas mixture, namely, the refractive index decreases with an increase in the portion of oxygen. It is shown that AlN films synthesized in a nitrogen plasma have a polycrystalline textured structure. An increase in the oxygen content leads to the formation of an amorphous phase. 